been published independently. Starting with the present volume, the symposia will appear as annual supplements to the journal Developmental Biology. This volume contains some most interesting and useful articles which will interest nearly all embryologists. My only criticism is the title. This was presumably chosen because, as happened in the previous year, tho contributed articles have no special feature in common. Though they concern control mechanisms in development, so do a great many others not covered here. To describe these simply as "Essays in Developmental Biology" would be an equally informative, and to some a less misleading, way of describing the contents, which are now considered separately.

The first three papers concern eytoplasmic organelles which contain DNA. Bogorad describes the development of plastids from a biochernical point of view and devotes special attention to changes in RNA metabolism and RNA polymerase activity that immediately follow illumination. Tatum and Luck are primarily concerned with the analysis of some slow-growing Neurospora mutants which show non-nuclear inheritance and lead to quantitative, but not qualitative, changes in cytochromes $a, b$ and $c$. Sir John Randall and his colleagues review the morphogenesis of flagella and the development of basal bodies which contain DNA, in Chlamydomonas.

Genetic "controlling elements" in maize are compared by McClintock with a number of not obviously related phenomena in other organisms. As the author says, there is still no direct evidence for comparable regulatory elements in organisms other than maize. Stebbins' contribution deals with factors which determine the direction of mitosis in plants and hence accounts for some important features of plant morphogenesis. Epphrussi and Weiss present some interesting ideas on certain aspects of the cell cycle in fused culture cells. They suggest that the coordination of events in the cell cycle may depend on the simultaneous initiation of DNA synthesis in all chromosomes, and that this is only achieved in chromosomes which are included in and attached to the same nuclear membrane. An extensive review of messenger RNA synthesis and of cytoplasmic DNA in sea urchin embryos, by Tyler, is orientated towards the currently popular topic of masked messenger RNA. It is suggested that developing cells become deter mined when messenger RNA is synthesized and masked. In relation to erythroid cell differentiation, London and colleagues discuss haem biosynthesis, and the part played by haem in regulating the synthesis of globin and assembly of haemoglobin. Auerbach summarizes, briefly, what is known of the identity of the tissue from which immunocompetent cells originate early in animal development. Finally, Sega discusses the early effects of oestrogen on the uterus, as well as his own work, which has shown the remarkable capacity of RNA extracted from hormone-stimulated uterine tissue to simulate most of the effects of the hormone, when introduced into ovariectomized animals

$$
\text { J. B. GURDON }
$$

\section{GENETICS OF FARM ANIMALS}

\section{Genetics and Animal Breeding}

By Ivar Johansson and Jan Rendel. Translated from the Swedish by Michael Taylor. Pp. xi +489 . (Oliver and Boyd: Edinburgh and London, 1968.) 105s.

THE authors' intention was to write a "general and fairly popular survey of the present knowledge about the genetics of farm animals and the methods of their improvement through breeding". In this they have succeeded admirably and the result is an authoritative and highly readable book which is certain to have a wide appeal. This is not simply a translation of the original Swedish text first published in 1963 . In preparing the English edition the material has been thoroughly revised, Professor J. C. Bowman rewriting the chapter on production char. acters in poultry, and some of the examples with specifically Swedish connotations have been replaced by others of more general interest.

In a general survey of a subject the amount of detail included must inevitably be curtailed. For example, the section on hereditary abnormalities deals only with some typical cases which are used to illustrate the various modes of inheritance, and for further information the reader is referred to other specialized works. A full bibliography has not been included, but the few selected references given at the end of each chapter have been carefully chosen, and will prove a good guide to those wishing to extend their study of animal genetics beyond the authors' self-imposed limits. The many other papers quoted are referred to in the text by author and year so that the complete reference can be found in an abstract journal if required.

The contents fall naturally into three parts. In the first, a brief but interesting historical survey is followed by three chapters on the physical basis of reproduction, Mendelian and population genetics. These provide a good outline of the basic principles and are a sound foundation for what follows, though some knowledge of statistics is a necessary prerequisite for a proper understanding of the introduction to population genetics.

The second and largest part contains an account of the inheritance of the more important qualitative and quantitative characteristics in farm livestock. The primary grouping of the subject matter is by characteristic rather than by species, so that the body size and carcass traits of cattle, sheep and pigs, for example, are all dealt with in the same chapter. This gives a very well integrated presentation.

Biochemical genetics could yield information of value to livestock breeding in the future, and the chapter on the inheritance of blood characteristics, with its useful discussion of practical applications, is worthy of note. Special mention should also be made of the section on the use of monozygous twins in research, a field in which Swedish scientists have made a considerable contribution.

The third and last part is, in some ways, the most interesting, for it is here that the authors draw together the information they have presented on economically important characteristics and discuss its application in practical schemes for the genetic improvement of farm livestock. Examples are given of methods currently used for evaluating the merit of breeding stock, and of improvement schemes now in operation.

The book provides an excellent introduction to the subject of animal breeding and will be welcomed by students of agriculture and veterinary science, and by others concemed with the improvement of animal production.

L. K. O'CONNOR

\section{SPECIFICITY OF ANTIBODIES}

The Structural Basis of Antibody Specificity

By David Pressman and Allan L. Grossberg. (Microbial and Molecular Biology Series.) Pp. xvii +279 . (Benjamin: New York and Amsterdam, 1968.) \$16.75.

INTEREST in immunology tends to alternate between the chemical and the cellular aspects of the subject. The great advances in the 'thirties were made when biochemists began to investigate antibodies as they would any other specific reagents, an approach associated with the names of Landsteiner, Heidelberger, Marrack and many others. But in time it became clear that the physicochemical approach, naively applied, was hopelessly blocked by the heterogeneity of the systems which were being studied, and more sophisticated analysis was both excessively complicated and biologically meaningless, though fun for the mathematicians. Interest at the same 